\title{
Corporate Knowledge Management System in the Conditions of Competitive Market
}

\author{
Mariya Lugovskaya \\ Department of Management and Marketing \\ Belgorod State National Research University \\ Belgorod, Russia \\ lugovskaya @ bsu.edu.ru \\ Tatyana Kameneva \\ Department of Sociology \\ Kursk State University, \\ Kursk, Russia \\ lugovskaya @ bsu.edu.ru \\ Viktoriya Malygina \\ Department of Social Technologies and Public Service \\ Belgorod State National Research University \\ Belgorod, Russia \\ lugovskaya@bsu.edu.ru
}

\begin{abstract}
Knowledge management for any business
\end{abstract} entity is currently one of the main directions of scientific research. Improvement of mechanisms of provision of educational services in higher educational institutions allow you to organize the innovation process of acquiring the required competencies graduates of the various training areas. The article deals with the theoretical foundations, the emergence of warehouses and developing the practice of a new type of management - knowledge management. The features of the increasingly important intangible assets of organizations as objects and as resources of the office are to group them according to various criteria, and also methodical recommendations on execution of the function of knowledge management. Based on the results of research and published works of different authors, the article specifically and concisely reveals the effect of control on skin reenie, learning and knowledge transfer. Much space is occupied by the problem of formation of leaders and structures, focused on the creation of new values using the methods of knowledge management. The conclusion about prospects from these positions' new institutional arrangements. It is extremely important to protect the traditional paradigm of higher education and organizational model of the University.

The complex structure of corporate knowledge, classified by type of activity, makes special requirements for the quality of management, which should represent a minimum administrative impact and provides for the transformation of the corporate culture of the university into a culture of trust and information exchange; institutionalizing the process. Effective management of corporate knowledge cannot be carried out only through organizational solutions and should provide for the formation of favorable conditions for their generation.

\author{
Maksim Selyukov \\ Department of Social Technologies and Public Service \\ Belgorod State National Research University \\ Belgorod, Russia \\ selyukov@bsu.edu.ru \\ Yurij Vash \\ Department of Social Technologies and Public Service \\ Belgorod State National Research University \\ Belgorod, Russia \\ lugovskaya@bsu.edu.ru
}

Keywords-knowledge, educational process, higher education, corporate knowledge repository of knowledge, knowledge management.

\section{INTRODUCTION}

Strengthening of the corporate beginnings in activity of the higher education, thus, keeps within a framework of the general tendencies of development of modern society which becomes more and more «korporativno structured», and the korporatokratiya plays in it a role of the most influential elite. But inclusion in the general logic of corporate processes means that during reproduction and the competition which more and more rigidly determine functioning of higher education institutions they with inevitability have to use those corporate resources which provide achievement of the goals. To number of such resources, organic to the nature of higher education institution, corporate knowledge belongs. This resource significantly distinguishes higher education institution from many corporations already because process of self-organization of high school life is initially focused on production of knowledge, their distribution and use both for internal development, and for change of the external environment. If in other corporations production of knowledge, as a rule, represents the necessary, but not dominating process, then in higher education institutions it becomes central, providing them potential advantages before competitors.

Many world-renowned universities realized «weight» of this advantage and widely use corporate knowledge for building of the opportunities, within educational and all economic space.

The deficiency of resources and limitation of opportunities which could be used for production, 
distribution and use of corporate knowledge is characteristic of most higher education institutions. At the same time the need for the effective technologies providing competitiveness on the relation as to the «capital», and foreign universities is sharply felt.

\section{METHODS}

General scientific methods of analysis and synthesis were used as research tools, as well as specific research methods such as: monographic method, abstract-logical, calculationgraphic, economic-statistical, comparative financialeconomic analysis, etc.

\section{MAIN PART}

The problems of knowledge management in recent years have become the subject of scientific research by many authors.

Consideration of the main provisions of postmodernism as a reflection on the reality of the knowledge society is largely devoted to the studies of such authors as V. Arshinov, Z. Bauman, U. Beck, V. Kutyrev, N. Mankovskaya and others.

As a social phenomenon, knowledge is studied in the works of P. Berger, T. Luckmann. The modern ontology of knowledge is analyzed based on the works of R.M. Aleinika, V.I. Arshinova, G. Behmann, I.P. Ilyina, V.L. Inozemtseva, V.I. Korogodina, J.-F. Lyotara, N.B. Mankovskaya et al. The works of researchers dealing with issues of social epistemology and studying the social aspects of the production and functioning of knowledge (I.T. Kasavin, A.G. Ovcharenko, M.A. Ponomarev) had a great influence on the formation of the concept of «knowledge».

The problems of the general theory of knowledge management are devoted to the research of famous domestic and foreign scientists, such as L.I. Abalkin, M. Abramovich, V.V. Glukhova, A.A. Dynkin, G. B. Kleiner, B.Z. Milner et al. They pay great attention to the processes of development of organizations through increasing investments in scientific research, creating mechanisms for stimulating, attracting and using scientific achievements in production.

The aim of the study is the scientific substantiation of the corporate knowledge management system of provincial universities through the development and implementation of algorithmic procedures and operations.

The main feature of corporate knowledge distinguishing them from other types of knowledge with which the higher education institution operates is that they are initially generated as the resource which is directly intended for ensuring activity of institution of higher education as specific corporation and realization of its functions (Schon, 2011).

Process of formation, distribution and use of corporate knowledge in the Russian provincial higher education institutions is characterized by a complex of problems now. First of all they are connected with quality of knowledge, a considerable part from which do not conform to requirements of both internal, and external clients. At the same time only a smaller part of actors of high school space has an idea of technologies of formation and use of corporate knowledge; workers are insufficiently motivated to participation in this activity. The main reasons for these problems are connected with deformation of organizational conditions of management of corporate knowledge in higher education institutions (Becker, 2015). Practice of management of knowledge has the bureaucratic nature and is a consequence of excessive formalization of educational activity. In the bureaucratic environment the bureaucratic «quasiknowledge» deprived of actual content and a little connected with science is often generated and used. The organizational structure of management of corporate knowledge within which any division actually specially is not engaged in this work is non-optimal, it is carried out with orientation to a situation and without necessary accounting of strategic tasks.

Improvement of a control system of corporate knowledge in provincial higher education institution includes two aspects: substantial and semantic and applied. The substantial and semantic aspect is connected with the change of the relation to a phenomenon of corporate knowledge which is expressed in a statement at participants of educational process of a fair idea of the maintenance of this phenomenon and its value; giving to corporate knowledge of the status of a social institution; motivations of participants of educational activity. The applied aspect causes structuring subjects of management of corporate knowledge; algorithmization of procedures of their formation, distribution and application; definition of translators of corporate knowledge; incorporation of the organizational structure exercising control of corporate knowledge in the developed management system. The central place among these tasks is taken by the process algorithmization providing forming on a uniform sample of a complex of social technologies (Lugovskaya, 2016; Gulyaev, Selyukov, Nadutkina, Lugovskaya, Davtyan, 2018).

The concept of system and regular updating of corporate knowledge by design and introduction of the mechanism of their production, distribution and use in the educational environment of higher education institution is offered. Implementation of the concept assumes the solution of a number of tasks. Treat them: structuring subjects of management of corporate knowledge; algorithmization of procedures of their formation, distribution and application; definition of translators of corporate knowledge; formation of organizational structure of management.

In formation of new model of management of corporate knowledge in higher education institution the algorithm with which in compliance the procedures providing realization of processes of their production, distribution and use are built has to execute a role of a backbone factor. On "entrance" of this algorithm there are needs of actors of high school space, at "exit" - practice of sale of corporate knowledge to external clients. Procedures of an algorithm are: producing corporate knowledge, their collecting, storage, distribution, application, monitoring, sale.

Realization of an algorithm will allow to give to management process of quality of social technology. At the same time each of procedures in it has to act as microtechnology. The flexibility of an algorithm will be provided with the variability of decisions allowed within the separate procedures.

The Center created on the basis of high school library, which is using its resource opportunities and gradually modifying them in compliance with new tasks has to become a kernel of a control system of corporate knowledge in 
provincial higher education institution. Activity of the Center will allow to improve quality of scientific developments; to increase speed and to increase efficiency of adoption of administrative decisions; to expand a range of the products and services offered by higher education institution; to attract new categories of clients; to reduce conflictness between actors of high school space (Hammer, Champy, 2003).

TABLE I. AWARENESS OF FACULTY AND RESEARCHERS ABOUT THE GOALS AND OBJECTIVES OF THE ORGANIZATION OF CORPORATE KNOWLEDGE (\% OF THE NUMBER OF RESPONDENTS)

\begin{tabular}{|c|c|c|}
\hline \multirow{2}{*}{$\begin{array}{c}\text { Do you have a good idea of the goals and objectives } \\
\text { of the organization of corporate knowledge of the } \\
\text { university? }\end{array}$} & \multicolumn{2}{|c|}{ Total } \\
\hline & $a b s$. & $\%$ \\
\hline Yes & 53 & 11,62 \\
\hline I present in general terms & 125 & 27,41 \\
\hline Vaguely imagine & 145 & 31,80 \\
\hline I can not imagine & 115 & 25,22 \\
\hline Difficult to answer & 17 & 3,95 \\
\hline
\end{tabular}

In the activity the Center has to lean on network of tutors, - the experts who are responsible for concrete activity of higher education institution to whose duties performance of processes of collecting, marking and entering of corporate knowledge into a repository and also interaction with consumers on all questions concerning filtration and the subsequent distribution of corporate knowledge belongs (Schultz, Peltier, 2013). Training of such tutors has to be carried out within the special high school project and at the expense of resources of institution of higher education.

Results of social research «Corporate knowledge in practice of control of higher education institution» exercised of the author from August, 2015 to February, 2016 allows to draw a number of the following conclusions. The sample of administrative employees of higher education institution made 225 respondents; the staff of higher education institution and teachers -450 respondents. 30 experts were among the scientists specializing in the field of management, employees of public authorities;

As the important indicators characterizing dispositions of participants of process of management of corporate knowledge of provincial higher education institution are allocated: level of knowledge of corporate knowledge; level of competence of the relation of their formation and use; assessment of process and conditions of their formation, structurization and use; perception of the barriers arising at management of corporate knowledge (Bowen, 2007).

1. Level of knowledge of corporate knowledge. The deficiency of information on corporate knowledge is characteristic of teachers and the staff of higher education institutions. Only 19,96\% among them are familiar with this term, «heard about a little it» $44,30 \%$ of respondents.

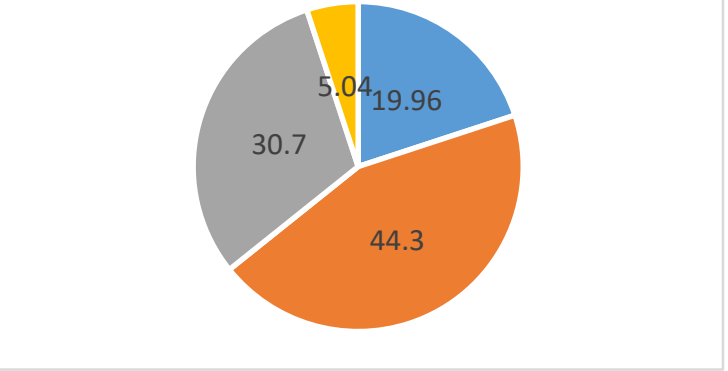

Fig.1. Corporate knowledge awareness

In particular, only $11.62 \%$ of faculty and staff answered unequivocally to the question «Do you have a good idea of

the goals and objectives of the organization of the university's corporate knowledge?»

Thereby the obvious paradox is fixed: in the organization which content of activity is defined by systematic functioning of corporate knowledge (namely such organization is the higher education institution) only a smaller part of workers has an idea of various aspects of their formation and use. The obtained data indicate that corporate knowledge in provincial higher education institution often extends without participation of their creators (scientists and teachers) that is typical for bureaucratic systems.

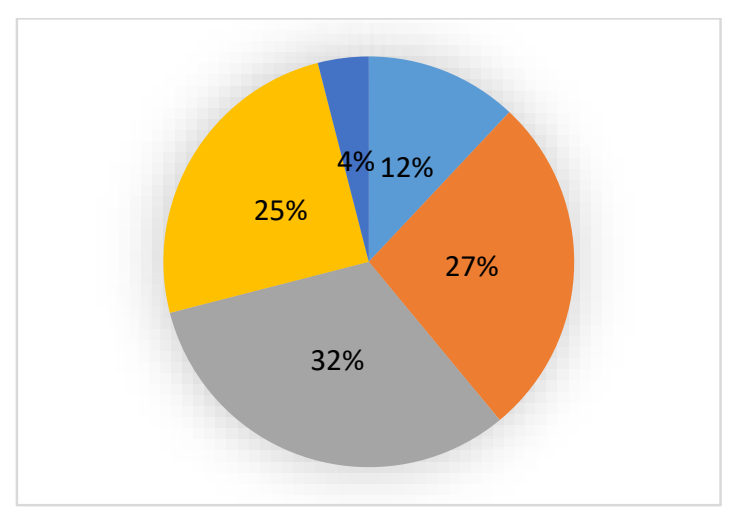

Fig.2. Do you well imagine the goals and objectives of the process of organizing corporate knowledge of a university? 
As can be seen from the presented figure, only $11.62 \%$ of respondents are well aware of the process of organizing corporate knowledge, the rest have a rather vague idea of it.

A noticeable similarity in the distribution of responses of teachers and staff in provincial universities about the level of awareness of the goals and objectives of the process of organizing corporate knowledge indicates the homogeneity of the processes occurring in universities.

2. Level of competence of the field of formation and use of corporate knowledge is characterized by blurring of ideas of opportunities of corporate knowledge both at administrators, and at the staff of higher education institutions. As a result of only $25,49 \%$ of teachers and research associates of higher educational institutions fully use them in the practice (at the same time 15,82\% answer that would be desirable to use this knowledge more). Most often corporate knowledge is demanded by administrative workers. $66,82 \%$ from them note the fact of their use in practical activities. This indicator is steady on regions and confirms that life cycle of knowledge in provincial higher education institutions is focused mainly on bureaucratic requirements. In it their limited functionality and a source of problems of their production, distribution and use is shown.

TABLE II. THE USE OF KNOWLEDGE ABOUT THE UNIVERSITY STAFF AND FACULTY

\begin{tabular}{|c|c|c|}
\hline \multirow{2}{*}{$\begin{array}{l}\text { To what extent are the knowledge about the university available } \\
\text { to you? }\end{array}$} & \multicolumn{2}{|c|}{ Total } \\
\hline & abs. & $\%$ \\
\hline Fully & 116 & 25,49 \\
\hline Partially & 219 & 48,13 \\
\hline Not enough & 28 & 6,15 \\
\hline I would like more & 72 & 15,82 \\
\hline Difficult to answer & 20 & 4,40 \\
\hline
\end{tabular}

Referred insufficiency of knowledge to number of such problems of $43,64 \%$ of teachers; $22,59 \%$ - lack of an opportunity to inform of values and vision of the obtained information wide audience; 39,04\% - dispersion of knowledge, both on sources, and on acquisition time; $15,79 \%$ unauthenticity; $8,77 \%$ - impossibility of immediate use.

3. Assessment of process of formation, structurization and use of knowledge. Process of production, distribution and use of corporate knowledge in provincial higher education institutions now practically, is not institutionalized and is carried out spontaneously. It did not include almost the teachers and employees having very uncertain idea of corporate knowledge. It is indicative that $50,44 \%$ among them found it difficult to express to it the relation, the Insufficient institutionalization of process, on the one hand, creates considerable difficulties for formation of a control system; on the other hand, allows to carry out this activity «from scratch», without spending the considerable efforts to transformation which developed earlier, but inefficient institutions.

4. Assessment of conditions of formation, structurization and use of knowledge. The research revealed contradictions between external (expert) assessment of conditions of management of corporate knowledge in provincial higher education institutions and internal assessment of the developed control system (Schweidel, Moe, 2014). Most of experts positively estimate organizational and personnel conditions. But, in opinion, internal clients in the surveyed provincial higher education institutions, as a rule, there was no control system of knowledge. The principles of its formation are not defined (only $24,22 \%$ of administrative employees consider successful the solution of this task). Only $24,66 \%$ believe that indicators of assessment of functioning of knowledge are accurately formulated; only $19,73 \%$ - are defined organizational mechanisms of management of knowledge.

TABLE III. DISTRIBUTION OF EMPLOYEES' ANSWERS TO THE QUESTION OF HOW CLEARLY THE FOLLOWING ELEMENTS ARE DEFINED IN YOUR UNIVERSITY

\begin{tabular}{|c|c|c|c|c|c|c|c|c|}
\hline \multirow{2}{*}{$\begin{array}{l}\text { How clearly are the following elements } \\
\text { defined in the university? }\end{array}$} & \multicolumn{2}{|c|}{ Clear enough } & \multicolumn{2}{|c|}{ Basically } & \multicolumn{2}{|c|}{ Not defined } & \multicolumn{2}{|c|}{ Difficult to answer } \\
\hline & abs. & $\%$ & abs. & $\%$ & $a b s$. & $\%$ & $a b s$. & $\%$ \\
\hline $\begin{array}{c}\text { Objectives of the emerging information } \\
\text { system for the updating of educational } \\
\text { services }\end{array}$ & 84 & 37,67 & 111 & 49,78 & 12 & 5,38 & 16 & 7,17 \\
\hline $\begin{array}{l}\text { Principles of formation of the system of } \\
\text { corporate knowledge of the university }\end{array}$ & 54 & 24,22 & 119 & 53,36 & 26 & 11,66 & 24 & 10,76 \\
\hline $\begin{array}{l}\text { Mechanism of management of corporate } \\
\text { knowledge of the university }\end{array}$ & 44 & 19,73 & 114 & 51,12 & 40 & 17,94 & 25 & 11,21 \\
\hline $\begin{array}{l}\text { Evaluation of the results of the } \\
\text { implementation of system indicators }\end{array}$ & 55 & 24,66 & 95 & 42,60 & 41 & 18,39 & 33 & 14,35 \\
\hline
\end{tabular}

If process of a regulation of management of corporate knowledge nevertheless, to some extent, is implemented in provincial higher education institution, then the situation with formation of the organizational structures which are carrying out this activity extremely difficult is. 
When assessing the degree of solution to corporate knowledge management problems, we used a scale that provides not only polar, but also intermediate answers. Its application allows one to determine indices (weighted average coefficients) for each of the research positions - in this case, for the elements of the formation of the corporate knowledge system of the university. The maximum possible value of the index is " +1 " (full, unambiguous definition), the minimum possible - "-1" (full, unambiguous indetermination), i.e. the index clearly demonstrates whether the situation is positive or critical.

With respect to the analyzed elements, the indices were:

- the goals of the emerging information system for updating educational services - 0.618;

- principles of the formation of the corporate knowledge system of the university - 0.509 ;

- a mechanism for managing corporate knowledge of the university - 0.452 ;

- assessment of the results of the implementation of system indicators -0.459 .

Thus, on the basis of the data obtained, it can be argued that at present in universities the most difficult situation is with the definition of the organizational mechanism for managing corporate knowledge and the assessment of this process. The complexity of solving these problems is obvious and is determined by several circumstances:

- firstly, the lack of optimality in building the university management system, which, on the one hand, has noticeably changed in recent years (within universities, in particular, relatively autonomous institutions have been created, in a number of universities departments have been formed that united traditional management, etc.);

- on the other hand, the changes did not significantly increase the degree of flexibility of the administrative system, did not give it significant additional opportunities for building the cognitive potential of the institutions;

- secondly, the conflict between the internal and external systems for assessing the functioning of educational institutions was clearly indicated, which was more or less consistently resolved by reformatting the internal one for external parameters that are not always adequate to the tasks being solved. This ultimately led to demotivation of many teachers and staff, their disorientation in relation to the real guidelines of their professional activities. Including, in relation to the knowledge functioning in the university space.

- thirdly, both the problems of forming a mechanism for managing corporate knowledge and the problems of criteria for their assessment have remained aside from the mainstream scientific developments of university researchers. Largely because the justification of the formal models proposed to the institutions looked like an apologetics for unpopular decisions, and the administration did not consider alternative models.

5. Perception of the barriers arising in process of management of corporate knowledge. During management of corporate knowledge there is a complex of the barriers which are defined by character of unresolved problems. Are among them: the barrier of poor quality connected with incompleteness, irrelevance and not long-standing trust of knowledge; technological, defined by not readiness of procedures of their functioning; organizational, expressed in imperfection of the mechanism of management.

Thus, process of management of corporate knowledge in provincial higher education institutions is determined now, mainly, by the bureaucratic interest of the administration which is guided mainly by formal indicators that leads to emergence and distribution of the «quasibureaucratic» iterations of corporate knowledge of little use or unsuitable in general for practical use. Preservation of this tendency leads to emergence of risk of substantial «erosion» of knowledge, emphasis of attention on process of its registration to the detriment of production and distribution.

\section{CONCLUSION}

The study allows us to assert that in the modern world, the importance of the phenomenon of corporate knowledge is constantly increasing, acting as part of the purposefully created intellectual capital of an organization, reflecting the laws of the objective world and the functioning of artificially created systems that are of an information nature, which are the result of synergy of individual and group knowledge. This type of knowledge arises in the process of corporate communications and is capable of regular controlled reproduction.

The upward trend in the importance of corporate knowledge is determined by a complex of reasons globally related to the growing role of information, strengthening of corporate principles in the management of organizations, increasing competition and the need to protect the results of intellectual activity. Locally, it is determined by the search for mechanisms that provide actors operating in various spheres of life with additional benefits through the use of intangible (mainly intellectual) resources.

In the conclusion the research results are summed up, practical recommendations to provincial higher education institutions are formulated.

In particular, it is offered:

- to develop and realize the road map of formation of a control system of corporate knowledge;

- to prepare and adopt the administrative regulations defining procedures of production, distribution and use of corporate knowledge including an order of their sale to the external client;

- on the basis of high school libraries to create control centers of corporate knowledge;

- to create repositories of corporate knowledge in libraries;

- to carry out the program of training of specialists in the sphere of management of corporate knowledge and tutors within the system of additional professional education;

- to enter into practice annual monitoring of assessment of corporate knowledge on the basis of criteria objective and clear to workers;

- to include indicators of participation in process of development, distribution and use of corporate knowledge to practice of rating of workers; 
- on the high school website to create an electronic resource within which the perspective of management of corporate knowledge will be discussed;

- to stimulate development of the marketing projects directed to the organization of system of sale of corporate knowledge to external consumers.

\section{REFERENCES}

[1] H. R. Bowen, Investment in learning : the individual and social value of American higher education, $507 \mathrm{p}$.

[2] M. Hammer, J. Champy Reengineering the corporation: a manifesto for business revolution , 2003, $187 \mathrm{p}$.

[3] P. Bourdieu, "The forms of capital. Handbook of Theory and Research for the sociology of education" ,2016, pp. 241-258.

[4] G.Becker, "Human Capital: a theoretical and empirical analysiswith special reference to education". National Bureau of Economic Research, 3 (1), 2015, pp.147-158

[5] I. Gulyaev, M. Selyukov, I. Nadutkina, M. Lugovskaya, D. Davtyan "Consolidation Potential of the Educational Community". The Journal of Social Sciences Research, 1, 2018, pp. 65-68

[6] M.V. Lugovskaya "Management in the Development of Higher Educational Institutions of Russia. International Business Management, 26, 2016, pp. 6013-6018.

[7] H. Reschke, "Projectmanagement: Grundlagen, 2004, 72 p.

[8] D. A. Schon, "Beyond the Stable State New". Random House, 4, 2011, pp. 211-221

[9] D. E. Schultz, J. Peltier, "Social media's slippery slope: Challenges, opportunities and future research directions. Journal of Research in Interactive Marketing", 7(2), 2013, pp.86-99.

[10] Schweidel, D. A., Moe, W.W., "Listening in on socialmedia: A joint model of sentiment and venue format choice. Journal of Marketing Research, 51(4), 2014, pp. 387-402.

[11] C. J. Thompson, G. Coskuner-Balli 2007. "Countervailing market responses to corporate co-optation and the ideological recruitment of consumption communities". Journal of Consumer Research, 34(2), pp. 135-152.

[12] M. Weber, Economy Tübingen human and society. Outline of understanding sociology, 2006, 944p.

[13] G. Zaitman, Innovations and organizations, 2002, 212 p. 